\title{
MOdern PARking Solutions For SMart Cities
}

\author{
Mladen Babic, Aleksandar Vekic, Milos Stanojevic, Gordana Ostojic, \\ Jelena Borocki \& Stevan Stankovski
}
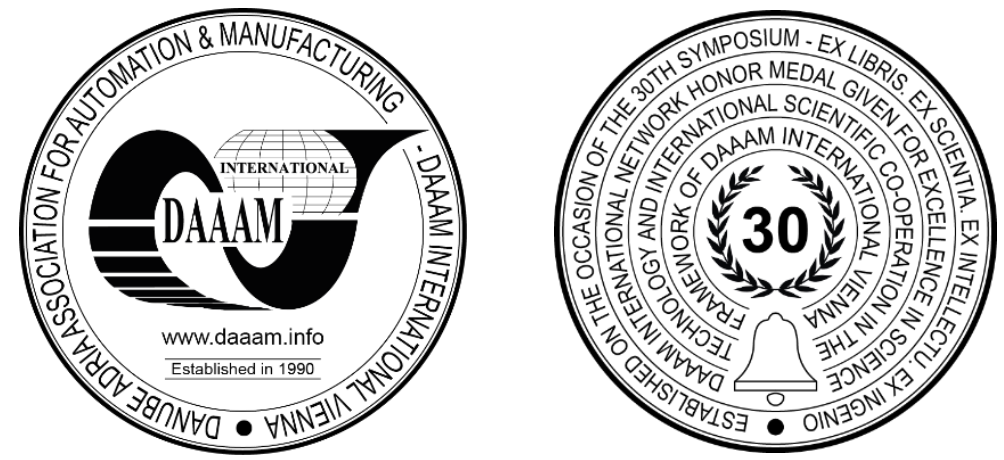

This Publication has to be referred as: Babic, M[laden]; Vekic, A[leksandar]; Stanojevic, M[ilos]; Ostojic, G[ordana]; Borocki, J[elena] \& Stankovski, S[tevan] (2019). Modern Parking Solutions for Smart Cities, Proceedings of the 30th DAAAM International Symposium, pp.1075-1083, B. Katalinic (Ed.), Published by DAAAM International, ISBN 9783-902734-22-8, ISSN 1726-9679, Vienna, Austria

DOI: $10.2507 / 30$ th.daaam.proceedings. 150

\begin{abstract}
The increasing number of urban areas conditioned by increasing number of people has led to significant innovations in the concept of living. The implementation and widespread use of modern technologies have enabled the rapid development of the smart cities. As population growth is accompanied by an increase in the number of cars and other vehicles, one of the most important problems facing cities is the development of an efficient parking system. Today's biggest problem in big cities is finding free parking spot, but also it is important to consider problems that arise in form of: longer time spent on cruising for parking, which increases pollution through the emission of $\mathrm{CO} 2$, more frequent traffic accidents, and a higher level of requests regarding the maintenance of traffic infrastructure. In order to successfully solve these problems with the adequate use of modern and advanced technologies, it is necessary to establish an effective planning system by the innovative parking management. This paper aims to show and compare some of the most important parking solutions in modern cities, as well as the use of advanced technologies for this purpose.
\end{abstract}

Keywords: modern technologies; parking solutions; smart cities; innovation

\section{Introduction}

Today a numerous city administration trying to give effective answers on this complex question of parking problem, through finding and implementing various innovative solutions. This usually requires a considerable amount of time and a high level of investment. Also, this requests willingness to adapt to change, and constant search for solutions and innovations. Schumpeter (1942) defined innovation as "process of industrial mutation that incessantly revolutionizes the economic structure from within, incessantly destroying the old one, incessantly creating a new one" [1]. This research has aim to present different parking solution and their architecture, which are implemented in urban areas and smart cities.

Urban areas, today becomes smart cities through implementation of high technology. Smart cities can be defined as "connecting the physical infrastructure, the IT infrastructure, the social infrastructure, and the business infrastructure to leverage the collective intelligence of the city" [2]. This means the use of Smart Computing technologies to make the critical infrastructure components and services of a city — which include city administration, education, healthcare, public safety, real estate, transportation and utilities - more intelligent, interconnected and efficient [3].

This leads to optimization of traditional public services, such as transport and parking, lighting, surveillance and maintenance of public areas, preservation of cultural heritage, garbage collection, salubrity of hospitals, and school [4]. This infrastructure needs to provide unified, simple and economical access to public services, with number of benefits for citizens and city management. A huge number of IT companies are developing a wide range of software and hardware 
solutions for smart cities, and one of the main reasons for entering this market is profit-seeking [5]. Parking solutions is field in which many companies are now investing heavily and the car parking industry has tremendous potential since the parking problems in developing and developed countries is increasing [6].

The rapid changes that are taking place in the modern world cannot follow all areas of society at an equal pace. It often happens that one change affects the intensity of another, which is the case with the increase in the number of cars and parking spaces. The number of cars in the world is constantly increasing, but the number of parking spaces is limited by a number of factors, above all the lack of space to define them. Research shows that more than 70 million cars were produced, just in 2016 alone, that represents an increase of $5 \%$ compared to 2015. Finding a parking place in a busy city centre is often a frustrating task for many drivers; time and fuel are wasted in the quest for a vacant spot and traffic in the area increases due to the slow-moving vehicles circling around [7], also this situation leads to an increase in traffic accidents.

Parking solutions is field in which many companies are now investing heavily and the car parking industry has tremendous potential since the parking problems in developing and developed countries is increasing [8]. These solutions are supported with IoT infrastructure, in which the objects of everyday life are equipped with microcontrollers, transceivers for digital communication, and suitable protocol stacks that will make them able to communicate with one another and with the users, becoming an integral part of the Internet [8]. For the purpose to create new solutions of IoT, companies use hardware and software components. Hardware components include connected devices (e.g. sensors, meters actuators, smartphones, wearable) and the interconnecting network (e.g. cellular, Wi-Fi, Bluetooth, 5G). Software components include for instance vendor's device management systems, data storage platforms, and analytics and dashboards applications [9].

According to Pike Research - forecasting that the number of people living in cities will almost double - from 3.6 billion to 6.3 billion by 2050 - and the research firm expects that phenomenal growth will lead to similar growth in smart city initiatives, as well as a smart cities technology market expected to top \$20 billion in annual value by 2020 [10]. Cities must plan for population growth, and introduce a more sustainable, efficient, and livable model in urban development. Modern digital technologies offer the chance to create a balance between social, environmental, and economic opportunities that will be delivered through smart city planning, design, and construction [9].

\section{Implementation of smart parking solution in the smart cities}

Introduction of smart parking systems in the cities is one of the first conditions that cities become smart. Development of smart city infrastructure is crucial for implementation of smart parking solution. Smart cities use different parking solutions to satisfy their own needs, according to car number, environment, population, terrain configuration, standard of living, etc.

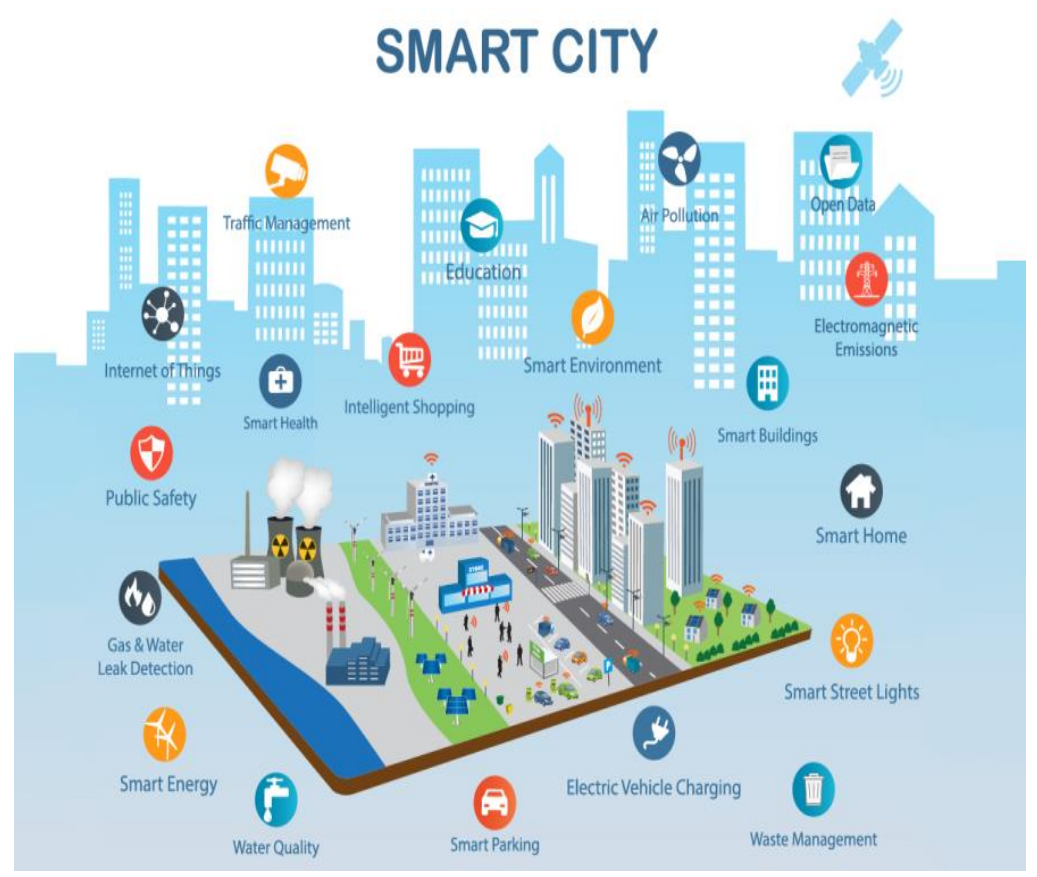

Fig. 1. Possible smart city infrastructure [11]

Smart Parking is a parking strategy that combines technology and human innovation in an effort to use as few resources as possible — such as fuel, time and space - to achieve faster, easier and denser parking of vehicles for the majority of 
time they remain idle [12]. Traffic on roads means the movement of road-users - including persons, streetcars, buses, vehicles, ridden or herded animals, and other conveyances; either singly or all together, while using the public right-ofway for travel purposes. Along with the increasing density of traffic, is the need to organize it [13].

The smart parking solutions use different components as: Occupancy Sensor, Gateway device, Server, Device. Different types of service which these solutions could offer are: Parking Monitoring, Parking Reservation, On-Street Parking, Off- Street Parking, GPS Parking Direction, Payment methods, etc. [12].

Smart parking technology benefits the customer and the parking operator in the following ways [14]:

- The customer can readily determine space availability prior to entering the garage and/or parking level.

- The customer can plan for their transit to public transportation with such smart parking systems employed at Park and Rides

- The parking operator can use the system data to develop or improve pricing strategies.

- The parking operator can use this system data to predict future parking patterns and trends.

- The parking operator can use this system data to prevent vehicle thefts.

- The parking operator can reduce the staffing requirements for traffic control within the facility.

- The system significantly reduces traffic-and the resulting vehicle emissions- by decreasing the time required for customers to locate open spaces.

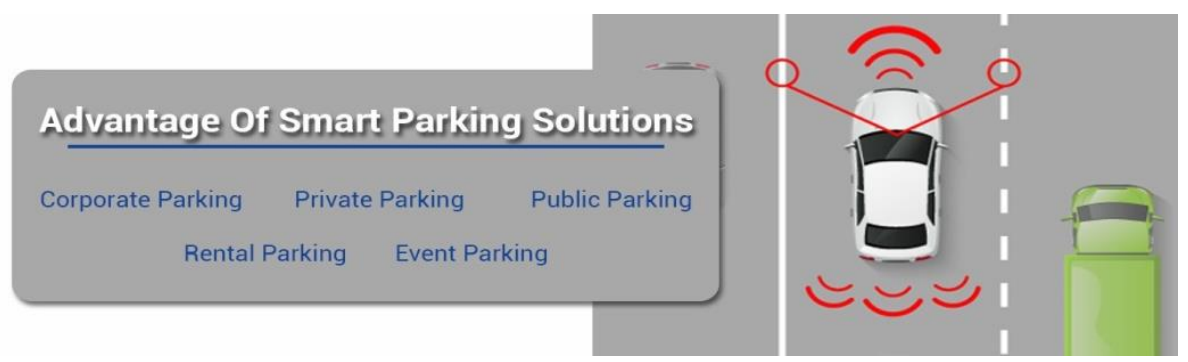

Fig. 2. Advantage of Smart Parking Solutions [15]

The parking management market size is expected to grow from USD 3.39 billion in 2018 to USD 5.15 billion by 2023, at a Compound Annual Growth Rate (CAGR) of 8.7\% during the forecast period. The major driver for the parking management market is expected to be the growing focus on seamless traffic flow and reduction in fuel consumption and increasing motor vehicle sales. The major restraining factor is could be the complexity in system integration [16]. The following companies appear as leaders in this field: Siemens, Cisco, Huawei, SWARCO, Streetline, WAViot, Ad Link, etc. Need for smooth traffic flow, business benefits to the parking site operators, and decreasing hardware and connectivity costs are the key drivers for the parking management industry [16].

\section{Possible innovative solutions}

\subsection{Dynamic pricing method}

One previous research [17] has shown the influence of certain factors on the problem of finding free parking spaces. In the metropolitan areas one of major challenges is parking problem, especially in the cities where parking resources are limited. Drivers usually have to cruise for a long time to find an available parking space [18]. A survey carried out in 2011 showed that $60 \%$ of drivers had the experience that they were so frustrated searching for parking that eventually gave up [19]. One of the main reasons why drivers are cruising for parking is that price for parking is low. Drivers who are cruising for parking are making more traffic congestion, so they need a lot of efforts to find free parking space. This problem has been discussed in research paper [20].

One of the ideas to reduce cruising for parking in cities is to take into account the price sensitivity and stochasticity of the parking demands. Poisson process was described in research paper [17] and presents how it can be used to influence parking price according to demands of parking spots. It's established a general parking reservation model, how the parking price varies with changing of demands and the number of vacant parking spaces. Considering the limited resources of parking spaces, it is possible to use parking price as a way of influence on driver's choice where they want to park. Interaction between prices and demands has an effect on user's choice, which transportation mode will be used. If the price would be lower, it would attract more and more people to park, but in another case, if price would get higher, it would urge people to use other types of public transport. 


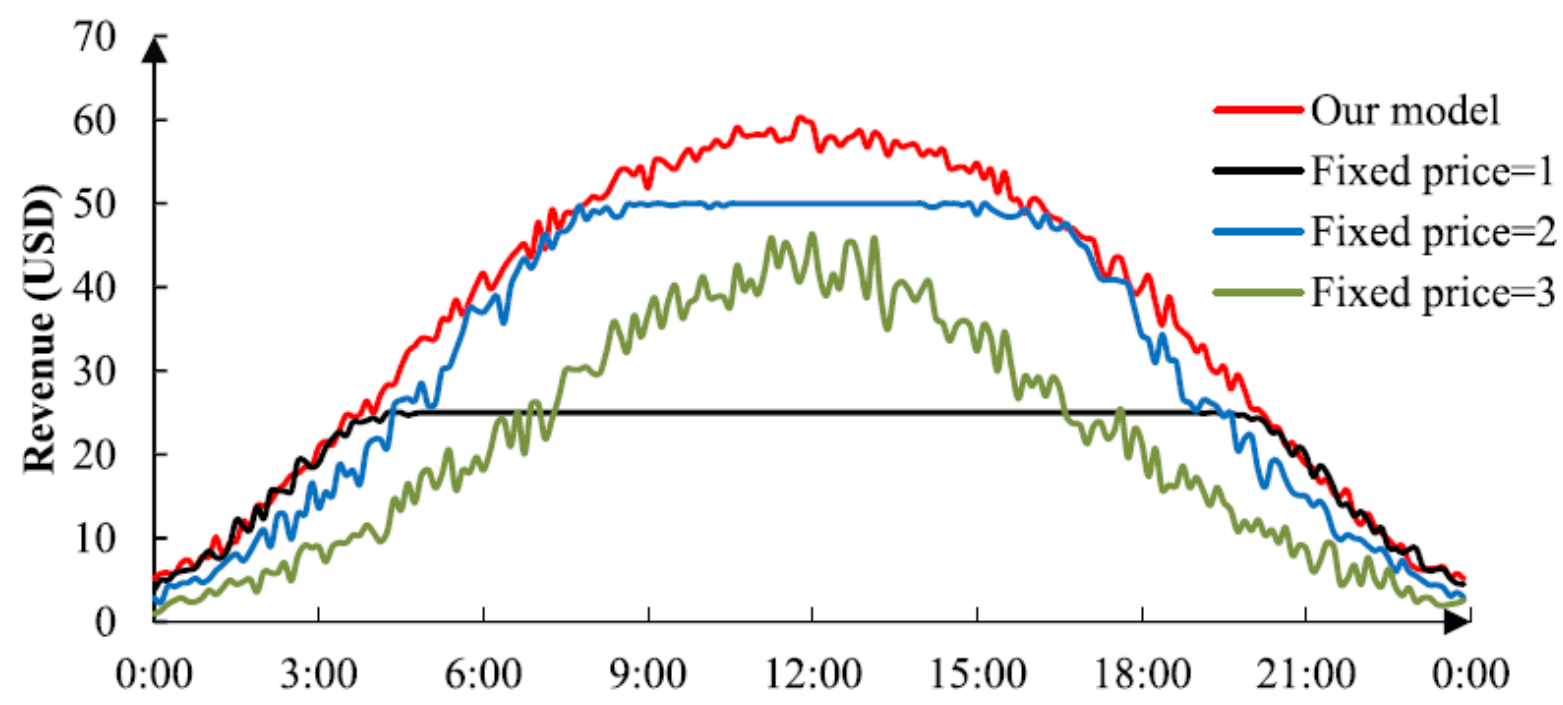

Fig. 3. Parking manager's revenue under different pricing policies [17]

Simulation results shown in Figure 1, point out that optimal policy maximizes parking manager's income and also saves traveler's time and lowers cruising expenses. Dynamic pricing represents a parking management system which tends to reduce traffic jams and pollution induced by cruising for parking.

\subsection{SmartPark system}

One of the solutions for parking problem in big cities is SmartPark system and it is described in research paper [21]. SmartPark system allows the user to monitor availability of parking lot in real-time, and it doesn't need any specialized infrastructure. System uses sensors in smartphones, Wi-Fi and cellular infrastructure. SmartPark aims to detect transportation mode and location of the user, but to preserve battery life of smartphone devices. One research presents how to use analytical approach for evaluation of parking availability even with small group of users. Simulation results show that SmartPark, benefiting from as little as $20 \%$ adoption rate, can estimate parking availability with accuracy above $90 \%$. Experimental results with the help of 12 volunteers show that SmartPark detects unparking events $97 \%$ of the time while triggering zero false positives [21].

System is aiming to make it easier for a driver to find empty parking spot, considering that in every moment someone could be parking vehicle and also someone could be unparking vehicle. When driver parks vehicle and leaves it, the application keeps monitoring drivers' movement. The moment driver returns to vehicle and pulls out of parking space application detects unparking event and sends information about empty parking lot.

In summary SmartPark system introduces [21]:

- The first system capable of detecting virtually every mode of transportation with accuracy approaching $100 \%$ while relying exclusively on the sensors available on modern smartphones.

- Algorithm for location matching, which relies on the readings from Wi-Fi and cellular base stations. Combined with the transportation mode detection, it enables SmartPark to detect unparking events with accuracy approaching $100 \%$ while having a negligible impact on battery life.

- Analytical approach for estimating parking availability even when only a fraction of users uses SmartPark.

- Evaluation in two ways: using simulations and in the wild. Simulations using a variety of configurations show that with as little as $10 \%$ of users adopting it, SmartPark can estimate parking availability with accuracy above $80 \%$. The accuracy reaches over $90 \%$ when $20 \%$ or more of the users adopt SmartPark. Over 30 h of experiments in the wild using 7 different smartphones with the help of 12 volunteers from 3 different cities show that: (a) SmartPark correctly detects unparking events $97 \%$ of the time while triggering zero false positives, and (b) SmartPark has a minimal impact on the battery consumption. Running SmartPark on a fully charged LG Google Nexus 5 for 5 h straight caused only about 4\% drop in battery charge. 


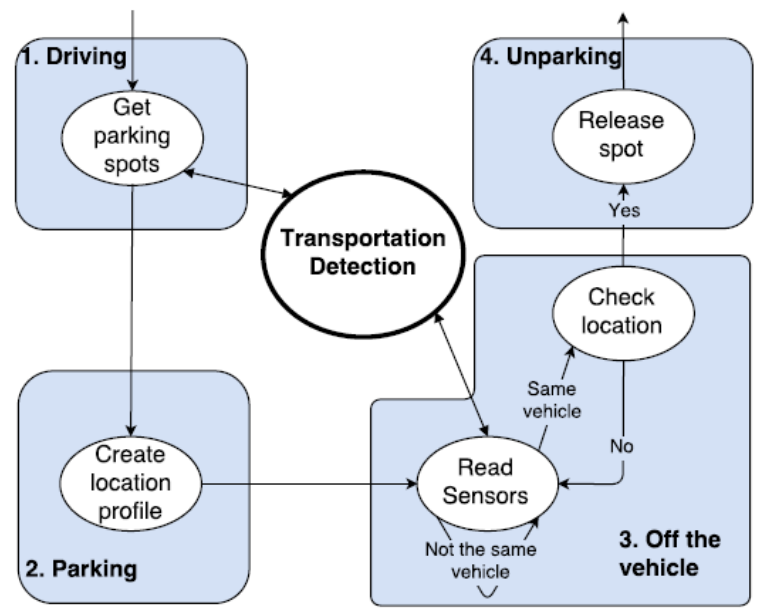

Fig. 4. SmartPark architecture for real-time parking availability [21]

In case that user is looking for parking spot, SmartPark system uses algorithm described in figure 4. Firstly, system determines the user's vehicle type. Then server receives inquiry via the Wi-Fi or cellular network about available parking spots close to user's location. When user parks a vehicle SmartPark scans exact location of the user, and saves it. After driver leaves vehicle, every 10 seconds system checks which transportation mode the driver is using. In case that SmartPark system detects that driver is using the same transportation mode as the one that was used while parking vehicle and if it is the same locations, the system recognizes that user is vacating the parking spot, and sends information about available parking spot to the server.

SmartPark system aims to determine two main tasks: which transportation mode the user uses and whether the user is at the same location. To do this basic idea of a SmartPark system, as already mentioned, is to use already-installed sensors found in smartphones. Smartphones come up with variety of built-in sensors such as:

- Accelerometer.

- Gyroscope.

- Orientation.

- Magnetic field sensor.

- Luminosity sensor.

- Atmospheric pressure sensor.

- Microphone.

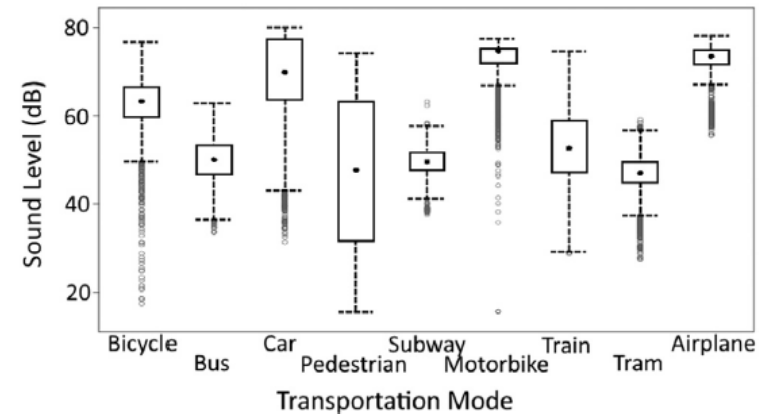

Fig. 5. Boxplot of sound level readings of nine transportation modes [21]

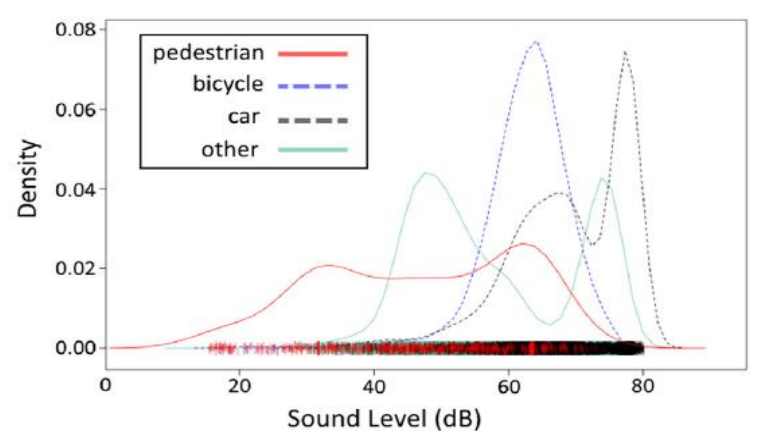

Fig. 6. Density function of sound level readings different transportation modes [21]

Figure 5. shows boxplot sound levels of nine different transportation vehicles. The motor bike generates the highest median value and a tight box: $50 \%$ of the readings are between 71 and $75 \mathrm{~dB}$ and almost all the readings are between 68 and $78 \mathrm{~dB}$. Figure 6. shows density function of sound level readings of the most commonly used transportation mode. 


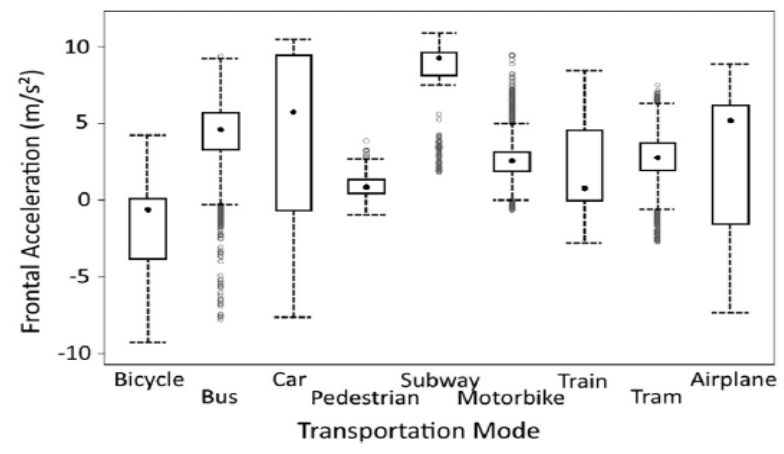

Fig.7. Boxplot of frontal acceleration readings of nine transportation modes [21]

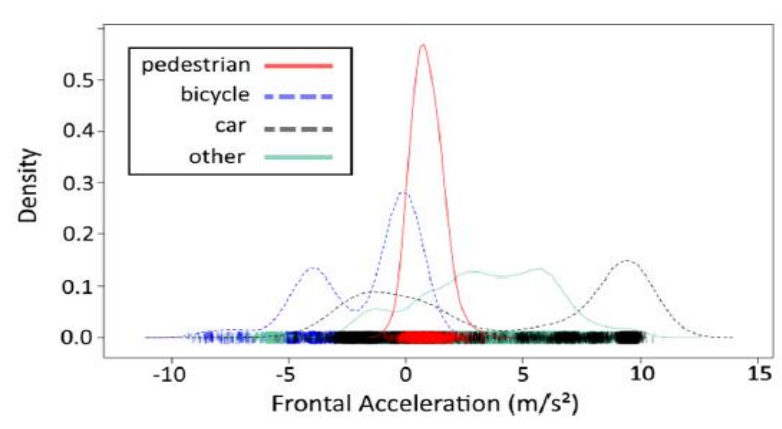

Fig. 8. Density function of frontal acceleration readings of different transportation modes [21]

Pictures above show that different types of transportation modes have different sensor readings. As shown at Figure 8. Density function has the highest read values for the transportation mode that has the most change in acceleration values, and it's clearly visible through sensor readings.

\subsection{Drivers location used for detecting free parking space}

Another solution for the problem of finding free parking space in smart cities is exploiting sensors in smartphones to collect real time parking availability information. In their research paper, authors Lan and Shih propose crowdsourcing solution [22]. Idea is to design smartphone based system to track driver's trajectory and to detect when they are about to leave their parking spot. To determine when the driver is leaving parking spot, authors rely on accuracy and efficiency of mobile phone sensors. It is considered to use a social network formed by drivers similar to Crowdpark platform [23]. In this architecture, a driver who is currently parked can provide advance notification when they are planning to leave, and this information can be sold to another driver that is willing to pay to reserve the parking spot [22]. First, driver gets required information, then he is allowed to arrive on parking spot and waits for seller to leave and then parks in his place. Buyer is charged only after he successfully parks his car in reserved spot. The idea is that every member in system gets unique ID when they are joining the social network, this way they real identity will not be revealed to the other users. Crowdsourcing approaches to parking are not new, but all other works in this require the drivers to manually report when they leave their parking spot [24]. Main difference in this system is that phone sensors detect when driver is about to leave parking spot by tracking drivers' trajectory.

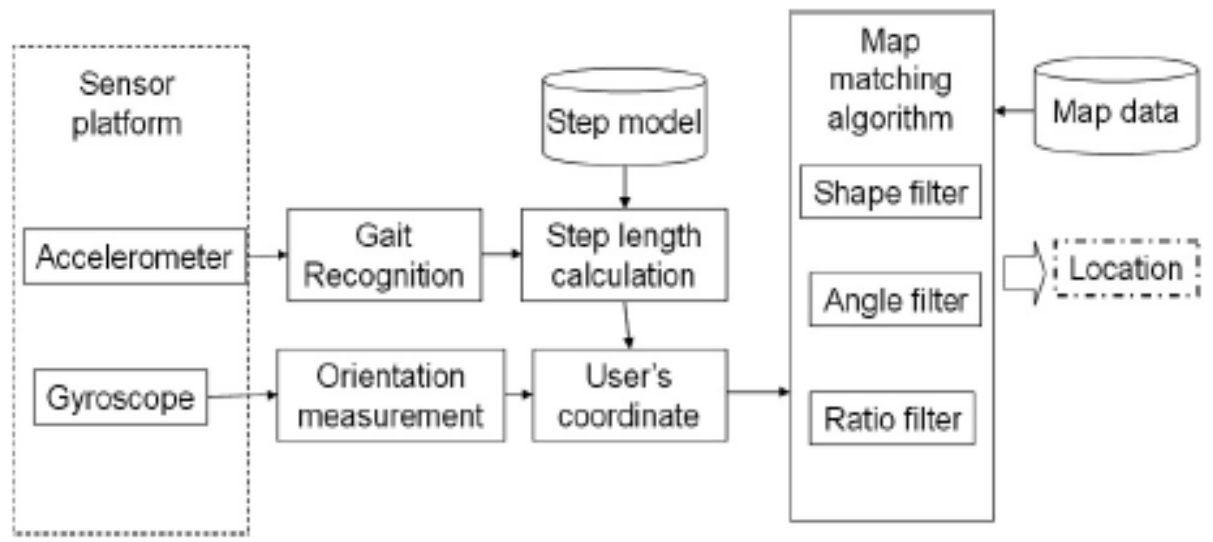

Fig. 9. The entire system architecture [22]

Detection of driver's location and trajectory is obtained using GPS data. Paper considers using personal dead reckoning or pedestrian dead reckoning (PDR) system to determine driver location even if driver is in a building. The PDR technique is based on using inertial sensors that are to be put on the user, so that it can be used in building without pre-installing beacon nodes or pre-building RF maps on surveys of the environment. Sensors are used to measure step 
length and heading direction. Generally, depending on where the sensors are placed, previous studies classified PDR systems into two types: foot- and waist mounted, as described in papers [24] [25].

This described configuration uses floor plans to detect exact location of driver, when he is in a building. This is one of main disadvantages of this approach, it requires database of floor plans. It is possible to achieve $98 \%$ accuracy, when locating walking distance of the driver. Overall error in determining exact location is about 0.48 meters.

\subsection{Use of genetic algorithm to predict available parking spot}

One of main difficulties that people have in today's living is finding parking spot when they are going to the shopping mall. Shopping malls are places where people come to buy things and entertain and they are always crowdie. It is common for every customer to waste some time and some quantity of fuel while looking for a free parking space. Even when customer finds a free place to park, there are also a lot of problems in terms of finding vehicle when they are leaving. Because of the poorly parking systems that are implemented in parking bays of shopping malls, also people park their vehicles by the road near shopping mall. After detecting the cause of the problem, it has been realized that the reason is not lack of parking space, but lack of efficient scheduling of vehicles to the parking space. One research paper proposes using of genetic algorithm to solve the scheduling issue [26]. Genetic algorithm is a very good optimization technique that iterates through different stages like selection, crossover, and mutation to obtain an optimal solution. It is based on theory of survival of the fittest [26].

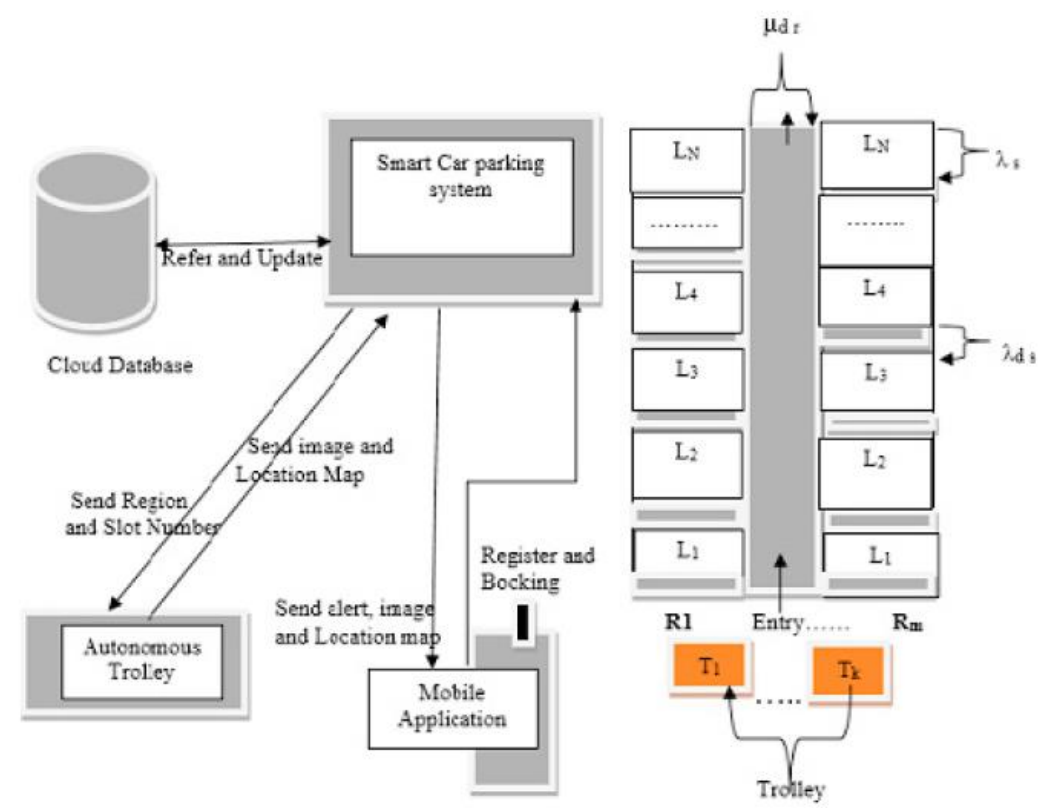

Fig. 10. System Overview and Internal structure [26]

System consists of android application, smart car parking system, cloud database and autonomous trolley, like it is shown at Figure 10. It is intended that customers use android application, so they can book the parking lot in advance. Users obtain user ID, to identify regular customers visiting the shopping mall. When booking, user needs to enter how long the parking lot is going to be occupied. User then pays the cost of active reservation using PayPal payment system. After parking time has exceeded duration of reservation, customers receive alert message. Customers are given grace period of 30 minutes to take vehicle from the parking lot, after that they will be extra charged at the exit. Payment and allotment details are stored in cloud database. Customers leave their vehicles at the entrance of the shopping mall and they can go and enjoy the shopping. The autonomous trolley takes vehicle from the entrance to empty parking lot that is determined by the system. The image and the map to their vehicle are sent to the customer mobile application, so they can have information that their vehicle is correctly parked. System gathers information about parking and unparking vehicles using ultrasonic sensors that are implemented on every parking spot.

\section{Conclusion}

Urban areas have limited number of parking spaces and it is difficult to enlarge their number and not to change city infrastructure, but as the number of people in cities grows it is necessary to find solution for the problems, like more often traffic jams, traffic accidents and longer time for finding free parking space. In addition to that best approach to this problem is to present new parking management system. Uprising of technology makes new possibilities for better management of parking spaces in metropolitan areas. In this paper there have been described some innovative solutions that could take significant part in future. 
Development of smart cities requires that parking management solutions be compatible to other components in the system. The key of perfect parking solution is to make complete use of current available technologies such as: IoT, Big Data, Machine Learning, and Cloud Technology.

Dynamic price management method shows how determined price of parking spaces in city center influence drivers to choose whether to drive their car or use some other transportation mode. Method proposes that price should get higher if the number of vacant parking lots gets lower and opposite, if the number of vacant parking lots gets higher price should get lower.

According to the solutions described in this paper, it is possible to conclude that the easiest solution for implementation is using sensors in smartphones. The reason for that is this system doesn't need changes in city infrastructure. SmartPark system solution offers completely automatic method to determine if the parking lot is occupied or not based on detecting location of driver and readings from smartphone sensors. SmartPark system uses Cloud Technology to store information about empty parking lots and location of the user. Main disadvantage of system is using Wi-Fi and cellular networks.

Another solution is using driver's location to determine vacant parking lots. This system depends on using GPS system in smartphones to determine driver's location. It is intended for driver to use smartphone application, so he has possibility to inform other users when he is planning to leave, and he can sell this information so another user could use his parking spot. This system is not completely automatic, because user needs to enter time of leaving manually.

In the paper, it is also described solution for garage parking in shopping malls. System is based on use of genetic algorithm to predict available parking lot. People have problems when they are trying to find where to park, but they also have difficulties to find where they parked their vehicle. This approach introduces using of trolley. Trolley picks a vehicle on the entrance to shopping mall and caries it to a vacant parking lot. Customers receive map to their vehicle over smartphone application, so they can find it when they are leaving. System uses algorithm to determine which parking lot will be free next so the trolley may park another vehicle in that place.

The issue about parking will be more and more important in the future. Further technologies development will be laver for creating and implementing new parking solutions. Cities always need to spend a long time to research the best possible solution for them just to make a right decision. The main findings of this paper can be used for future research on smart cities and modern parking solutions based on Internet infrastructure and modern technologies.

\section{Acknowledgement}

This research has been supported by the Provincial Secretariat for Higher Education and Scientific Research of Autonomous Province of Vojvodina, Republic of Serbia, through the project: "Implementation of IoT tracking system for fresh food produces from Vojvodina”, and Ministry of Education, Science and Technological Development, Government of the Republic of Serbia, through the projects: TR35001 and Grant 401-00-00589/2018-09.

\section{References}

[1] Schumpeter, J.A. (1942). Capitalism, Socialism and Democracy, 3rd edition, London: George Allen and Unwin, 1976.

[2] Harrison, C.; Eckman, B.; Hamilton, R.; Hartswick, P.; Kalagnanam, J.; Paraszczak, J. \& Williams, P. (2010). Foundations for Smarter Cities. IBM Journal of Research and Development, 54(4).

[3] Washburn, D.; Sindhu, U.; Balaouras, S. \& Dines, R. A. (2010). Helping CIOs Understand "Smart City" Initiatives: Defining the Smart City.

[4] Atzori, L.; Iera, A. \& Morabito, G. (2010) . The internet of things: A survey. Comput. Netw., Vol. 54, no. 15, pp. 2787-2805.

[5] Oláh, J.; Poop, J.; Máté, D. \& Hidayt. A. Y. (2019). Market structure and concentration ratio: evidence of IT companies in Hungary, Forum Scientiae Oeconomia, Vol.7, No.3, pp.1-13.

[6] Jog, Y.; Sajeev, A.; Vidwans, S. \& Mallick, C. (2015). Understanding smart and automated parking technology, International Journal of u-and e-Service, Science and Technology, 8(2), pp. 251-262. ISSN: 22079718.

[7] Polycarpou, E.; Lambrinos, L. \& Protopapadakis, E. (2013). Smart parking solutions for urban areas, In 2013 IEEE 14th International Symposium on" A World of Wireless, Mobile and Multimedia Networks"(WoWMoM), pp. 1-6, ISBN: 978-1-4673-5827-9.

[8] Jog, Y.; Sajeev, A.; Vidwans, S. \& Mallick, C. (2015). Understanding smart and automated parking technology, International Journal of u-and e-Service, Science and Technology, 8(2), pp. 251-262. ISSN: 22079718.

[9] Suzuki, L.R. (2017). Smart Cities IoT: Enablers and Technology Road Map. In: Rassia S., Pardalos P. (eds) Smart City Networks. Springer Optimization and Its Applications, Vol 125. Springer, Cham.

[10] SmartCitiesCouncil (2013). Pike Research, https://smartcitiescouncil.com/tags/pike-research, Accessed: 15 September 2019.

[11] Adtell Integration (2019). Smart Cities Infrastructure, http://adtellintegration.com/smart-cities-infrastructure/, Accessed: 04 October 2019.

[12] Infinite Information \& Technology (2019). IoT Smart City- What is smart parking?, http://www.infiniteinformationtechnology.com/iot-smart-city-what-is-smart-parking, Accessed: 02 October 2019. 
[13] Pokorny, P. (2018). A Comparison of Methods for The Identification of Traffic Levels in Cities, Annals of DAAAM \& Proceedings, 29, Vol. 29, pp. 0243-0249, DOI 10.2507/29th.daaam.proceedings.035.

[14] Reve, S. V., \& Choudhri, S. (2012). Management of car parking system using wireless sensor network. Int. J. Emerg. Technol. Adv. Eng, 2(7), pp. 262-268.

[15] Hackernoon (2019). How much will smart parking solutions improve 2019?, https://hackernoon.com/how-muchwill-smart-parking-solutions-improve-in-2019-fa1bac32cb77, Accessed 05 October 2019.

[16] Report Bayer (2019). Parking Management Market by Solution, Service, Deployment Type, Parking Site And Region - Global Forecast to 2023, https://www.reportbuyer.com/product/4208326/parking-management-market-bysolution-service-deployment-type-parking-site-and-region-global-forecast-to-2023.html, Accessed: 05 October 2019.

[17] Tian, Q.; Yanga, L.; Wanga, C. \& Huanga, H. J. (2018). Dynamic pricing for reservation-based parking system: A revenue management method, Transport Policy 71, pp. 36-44.

[18] Shoup, D.C. (2006). Cruising for parking, Transport Pol., Vol. 13, No. 6, pp. 479-486.

[19] IBM (2011). Global Parking Survey, http://www03.ibm.com/press/us/en/pressrelease/35515.wss, Accessed: 17 September 2019.

[20] Azari, K. A.; Arintono, S.; Hamid, H. \& Rahmat, R.A. (2013). Modelling demand under parking and cordon pricing policy, Transport Pol., Vol.25, pp.1-9.

[21] Krieg,J. G.; Jakllari, G.; Toma, H. \& Beylot, A.L. (2018). Unlocking the smartphone's sensors for smart city parking, Pervasive and mobile Computing, Vol. 43, pp. 78-95.

[22] Lan, K.C. \& Shih, W.Y. (2014). An intelligent driver location system for smart parking, Expert Systems with Applications, Vol. 41, pp. 2443-2456.

[23] Yan, T.; Hoh, B.; Ganesan, D.; Tracton, K.; Lwuchukwu, T. \& Lee, J. (2011). CrowdPark: A crowdsourcing-based parking reservation system for mobile phones. In UMASS Technical Report., Tech. Rep. UM-CS-2011-001.

[24] Alvarez, D.; Gonzalez, R. C.; Lopez, A. \& Alvarez, J. C. (2006). Comparison of step length estimators from wearable accelerometer devices. In 28th Annual international conference of the IEEE in engineering medicine and biology society (EMBS ‘06), pp. 5964-5967.

[25] Alvarez, J. C.; Gonzalez, R. C.; Alvarez, D.; Lopez, A. M. \& Rodriguez-Uria, J. (2007). Multisensor approach to walking distance estimation with foot inertial sensing. In 29th Annual international conference of the IEEE engineering in medicine and biology society (EMBS 2007), pp. 5719-5722.

[26] Thomasa, D. \& Kovoorb, B.C. (2018). A Genetic Algorithm Approach to Autonomous Smart Vehicle Parking system, Procedia Computer Science, Vol.125, pp. 68-76. 